\title{
Identification of At-Risk Inpatient Hospital Populations at the Community Level
}

\author{
Ronald Lagoe, Ruthie Lagoe \\ Hospital Executive Council: Syracuse, New York, USA \\ Email: hospexcl@cnymail.com
}

Received 26 June 2014; revised 22 July 2014; accepted 1 August 2014

Copyright (C) 2014 by authors and Scientific Research Publishing Inc.

This work is licensed under the Creative Commons Attribution International License (CC BY). http://creativecommons.org/licenses/by/4.0/

(c) (i) Open Access

\section{Abstract}

This study focused on hospital populations which account for large amounts of health care utilization at the community level in the metropolitan area of Syracuse, New York. It demonstrated that, between the two largest hospital inpatient services, adult medicine patients accounted for a larger number of excess hospital patient days than adult surgery over a two-year period. Adult medicine stays increased while adult surgery stays declined. Adult medicine also accounted for a larger number of excess inpatient days, an average daily census of 52.7 patients in 2013, although adult medicine outliers comprised only $2.4-2.5$ percent of discharges while adult surgery patients comprised 4.4 - 4.5 percent of discharges for these services. Adult medicine readmissions accounted for 79 - 81 percent of these adverse events for the combined hospital during the two-year period. Adult medicine complications accounted for 60 - 62 percent of complications in the two hospitals for which data were available. These data clearly demonstrate the challenges that adult medicine patients carry for providers as they attempt to improve the efficiency and outcomes of care in local communities. In the United States, payer reimbursement for the care of these patients frequently does not match the resources required as funding emphasizes surgical specialties and healthier patients. In metropolitan areas such as Syracuse, where local populations are aging or declining, the expenses of caring for these patients can become a major challenge for community providers.

\section{Keywords}

Hospitalization, Hospital Lengths of Stay, Hospital Readmissions, Hospital Complications

\section{Introduction}

In recent years, increased attention has focused on improving the efficiency and outcomes of health care in the United States and other western nations. This development has been supported by a recognition that the quantity 
of care does not necessarily equate with quality and that the focus of reimbursement should shift from the volume to the value of health services [1] [2].

Historically, rising health care expenses in the United States created incentives for improving the efficiency of care. These expenses led to the implementation of health maintenance organizations and hospital payments per discharge in the twentieth century, as well as Accountable Care Organizations and provider productivity adjustments in the twenty first century [3]. More recently, lower enrollment growth and lower utilization have been reported for some services. In recent years, the collective impact of these and other mechanisms has been associated with a reduction in the rate of growth of health care expenses in the United States [4] [5].

In the twenty first century, the role of improving health care outcomes as a means of improving the costs and quality of care has received greater attention. The relationship between outcomes and costs has been demonstrated for indicators including hospital inpatient complications and hospital readmissions [6]. The ability of providers and payers to monitor and address these issues has been supported by the development of computer software which uses standardized definitions and administrative data. This software has made it possible to identify and monitor health care outcomes using standardized definitions over multiple providers and extended periods of time. Through use of administrative data, the software has also made it possible to follow and evaluate large patient populations [7] [8].

At the national and regional levels, these changes have supported the development of policies and reimbursement mechanisms that encourage improvements in health care efficiency and outcomes. In the United States, these developments have represented a continuation of the leadership exerted by Medicare and other payers in health care reform and reimbursement. These have included the improvement of hospital efficiency through reimbursement by discharge and the improvement of quality of care through payment disincentives for adverse outcomes such as inpatient readmissions and complications [9] [10].

In the United States and elsewhere, these efforts have involved the identification of patient populations most at risk of high utilization and resource use at national and regional levels. It has been estimated that 5 percent of the United States population accounts for 49 percent of total health care spending [11]. Studies conducted in Canada have demonstrated that 5 percent of health care users are associated with 61 percent of hospital and home care expenses and 30 percent of physician service expenses [12] [13].

Addressing these challenges has required identification of populations most at risk in order to develop mechanisms to address them. Because the delivery of health care is a local process, these activities need to occur at the community level. It involves the development of planning data as well as the planning and implementation of initiatives to improve the process of care.

\section{Population and Methods}

The objective of this study was to identify inpatient populations with substantial potential for improvement of efficiency and outcomes in the hospitals of Syracuse, New York, a small metropolitan area located in upstate New York. These hospitals provide primary and secondary acute care services to a population of approximately 600,000. They also serve as the tertiary center for the eleven county Central New York Health Service area, which includes a population of approximately 1,400,000 (New York Statistical Information System, Unpublished data, 2012).

The acute care system of Syracuse includes Crouse Hospital (19,738 inpatient discharges excluding well newborns, 2013), St. Joseph's Hospital Health Center (25,771 inpatient discharges), and University Hospital of the State University of New York Upstate Medical Center (27,285 inpatient discharges). In 2011, Upstate University Hospital acquired Community General Hospital, the smallest acute care facility in the city (Hospital Executive Council, Unpublished data, 2014).

Historically, the hospitals of Syracuse have worked to improve the efficiency and outcomes of care in the community through their cooperative planning organization, the Hospital Executive Council. These efforts have included the development of programs to reduce inpatient lengths of stay through cooperation with local long term care providers and initiatives to improve the outcomes of care through reduction of inpatient complications and readmissions [14]-[17].

\subsection{Identification of Populations Related to Improvement of Hospital Efficiency}

The initial component of the study focused on identification of inpatient populations in the Syracuse hospitals 
that could most benefit from improvement of efficiency through length of stay reduction. This process involved the use of administrative data for each of the hospitals for 2012 and 2013.

For this component of the study, the inpatient populations for each of the three hospitals were identified for adult medicine and adult surgery. In order to develop a consistent analysis across the hospitals, the services were defined by All Patients Refined Diagnosis Related Groups.

For the analysis of opportunities for efficiency, lengths of stay in the Syracuse hospitals were compared with national populations with the same distributions of discharges by severity of illness. This procedure was employed in order to ensure that differences in stays that were identified did not result from variations in the degree of illness for the inpatient populations. For this analysis, the $3 \mathrm{M}^{\mathrm{TM}}$ All Patients Refined Diagnosis Related Groups and related severity of illness categories were employed. This system identifies a severity of illness of 1-Minor, 2-Moderate, 3-Major, or 4-Extreme, based on the principal and all secondary diagnoses, the principal and all secondary procedures, as well as the demographic characteristics of each hospital inpatient.

In this component of the study, the analysis focused on adult medical and surgical patients because these services included the largest numbers of inpatient discharges and potential for efficiency. The analysis was carried out for the individual Syracuse hospitals and for the combined hospitals.

In this analysis, efficiency was quantified as the unit difference between the hospital stay for the service and the severity adjusted national average at the unit level and the number of patient days saved or excess days that the difference in stays would generate. This analysis was employed for all discharges and for discharges with stays of 21 days or more for each service. The second analysis was developed in order to evaluate the specific impact of long stay patients on efficiency.

\subsection{Identification of Populations Related to Hospital Outcomes}

The second component of the analysis focused on populations in the Syracuse hospitals that could benefit most from improvement of outcomes of care. This component involved hospital inpatient readmissions within 30 days. It involved the use of administrative data for 2012 and 2013.

The inpatient populations of each of the Syracuse hospitals were identified by major services including adult medicine, adult surgery, pediatrics and mental health. In order to provide consistent information across the community, the services were identified using definitions based on All Patients Refined Diagnosis Related Groups.

For the analysis of opportunities related to patient outcomes, the Syracuse hospitals and their inpatient services were compared using the Potentially Preventable Readmissions software developed by $3 \mathrm{M}^{\mathrm{TM}}$ Health Information Services. This software identified readmissions to the same hospital within 30 days of the initial discharge based on the clinical relationship between the initial admission and the readmission. Readmissions were identified by service based on the All Patients Refined Diagnosis Related Group of the readmission. This classification is based on the principal diagnosis, the cause of the readmission.

For this component of the study, numbers of Potentially Preventable Readmissions within 30 days of the previous discharge were identified for adult medicine, adult surgery, pediatrics and mental health (including psychiatry and alcohol/substance abuse) in the Syracuse hospitals for 2012 and 2013. These data included numbers of readmissions and readmission rates per discharges within each service. The analysis focused on comparisons of numbers of readmissions and rates across the hospitals.

In addition to hospital readmissions, this component of the study included a brief review of numbers of hospital inpatient complications in the Syracuse hospitals. Because of limitations on the availability of data, this analysis included two acute care facilities, St. Joseph’s Hospital Health Center and Crouse Hospital.

Data for the analysis of hospital inpatient complications were identified using the Potentially Preventable Complications software developed by $3 \mathrm{M}^{\mathrm{TM}}$ Health Information Systems. This software identifies complications for a wide range of diagnoses that occur after inpatient admission using the Present on Admission indicator. In this methodology, secondary diagnoses that were not present at the time of the admission are candidates for inpatient complications.

\section{Results}

\subsection{Hospital Efficiency}

Data related to the first component of the analysis, which focused on hospital inpatient lengths of stay, are 
summarized in Table 1 and Table 2. These data include inpatient utilization and excess patient days for adult medicine and adult surgery in the Syracuse hospitals in 2012 and 2013.

The information in Table 1 demonstrated that, between 2012 and 2013, the mean length of stay for adult medicine in the combined hospitals increased from 5.14 to 5.21 days. The 0.07 increase in the combined hospitals was offset by a 0.14 increase in severity of illness, as the adjusted national average increased from 5.00 to 5.14

Table 1. Inpatient adult medicine and adult surgery mean lengths of stay, Syracuse Hospitals, 2012-2013.

\begin{tabular}{|c|c|c|c|c|c|}
\hline & \multicolumn{5}{|c|}{ Adult Medicine } \\
\hline & $\begin{array}{l}\text { Number of } \\
\text { Discharges }\end{array}$ & $\begin{array}{l}\text { Mean Length } \\
\text { of Stay }\end{array}$ & $\begin{array}{l}\text { Severity Adjusted } \\
\text { National Average }\end{array}$ & $\begin{array}{l}\text { Length of Stay } \\
\text { Difference }\end{array}$ & $\begin{array}{c}\text { Patient Days } \\
\text { Difference }\end{array}$ \\
\hline \multicolumn{6}{|l|}{ January-December 2012} \\
\hline Crouse Hospital & 8723 & 4.83 & 5.10 & -0.27 & -2355.21 \\
\hline St. Joseph’s Hospital & 13,268 & 5.09 & 4.88 & 0.21 & 2786.28 \\
\hline \multicolumn{6}{|l|}{ Health Center } \\
\hline Upstate University Hospital & 13,283 & 5.39 & 5.06 & 0.33 & 4383.39 \\
\hline \multicolumn{6}{|l|}{ SUNY UMU } \\
\hline Total & 35,274 & 5.14 & 5.00 & 0.14 & 4938.36 \\
\hline \multicolumn{6}{|l|}{ January-December 2013} \\
\hline Crouse Hospital & 8260 & 5.01 & 5.33 & -0.32 & -2643.20 \\
\hline St. Joseph’s Hospital & 12,734 & 5.12 & 4.99 & 0.13 & 1655.42 \\
\hline \multicolumn{6}{|l|}{ Health Center } \\
\hline Upstate University Hospital & 13,080 & 5.42 & 5.16 & 0.26 & 3400.80 \\
\hline \multicolumn{6}{|l|}{ SUNY UMU } \\
\hline \multirow[t]{2}{*}{ Total } & 34,074 & 5.21 & 5.14 & 0.07 & 2385.18 \\
\hline & \multicolumn{5}{|c|}{ Adult Surgery } \\
\hline \multicolumn{6}{|l|}{ January-December 2012} \\
\hline Crouse Hospital & 4825 & 4.53 & 5.00 & -0.47 & -2267.75 \\
\hline St. Joseph’s Hospital & 9192 & 5.31 & 5.35 & -0.04 & -367.68 \\
\hline \multicolumn{6}{|l|}{ Health Center } \\
\hline Upstate University Hospital & 6423 & 8.22 & 6.87 & 1.35 & 8671.05 \\
\hline \multicolumn{6}{|l|}{ SUNY UMU } \\
\hline Total & 20,440 & 6.04 & 5.75 & 0.29 & 5927.60 \\
\hline \multicolumn{6}{|l|}{ January-December 2013} \\
\hline Crouse Hospital & 4672 & 4.54 & 5.09 & -0.55 & -2569.60 \\
\hline St. Joseph’s Hospital & 9507 & 5.43 & 5.65 & -0.22 & -2091.54 \\
\hline \multicolumn{6}{|l|}{ Health Center } \\
\hline Upstate University Hospital & 6288 & 7.75 & 7.05 & 0.70 & 4401.60 \\
\hline \multicolumn{6}{|l|}{ SUNY UMU } \\
\hline Total & 20,467 & 5.94 & 5.95 & -0.01 & -204.67 \\
\hline
\end{tabular}

Sources: Crouse Hospital, St. Joseph’s Hospital Health Center, and Upstate University Hospital-SUNY UMU; 3M Health Information Systems. 
Table 2. Inpatient adult medicine and adult surgery mean lengths of stay, patients with stays greater than 20 days, Syracuse Hospitals, 2012-2013.

\begin{tabular}{|c|c|c|c|c|c|}
\hline & \multicolumn{5}{|c|}{ Adult Medicine } \\
\hline & $\begin{array}{l}\text { Number of } \\
\text { Discharges }\end{array}$ & $\begin{array}{l}\text { Mean Length } \\
\text { of Stay }\end{array}$ & $\begin{array}{l}\text { Severity Adjusted } \\
\text { National Average }\end{array}$ & $\begin{array}{l}\text { Length of Stay } \\
\text { Difference }\end{array}$ & $\begin{array}{l}\text { Patient Days } \\
\text { Difference }\end{array}$ \\
\hline \multicolumn{6}{|l|}{ January-December 2012} \\
\hline Crouse Hospital & 138 & 30.48 & 10.47 & 20.01 & 2761.38 \\
\hline St. Joseph’s Hospital & 279 & 32.99 & 9.34 & 23.65 & 6598.35 \\
\hline \multicolumn{6}{|l|}{ Health Center } \\
\hline Upstate University Hospital & 416 & 33.54 & 9.34 & 24.20 & $10,067.20$ \\
\hline \multicolumn{6}{|l|}{ SUNY UMU } \\
\hline Total & 833 & 32.85 & 9.53 & 23.32 & $19,425.56$ \\
\hline \multicolumn{6}{|l|}{ January-December 2013} \\
\hline Crouse Hospital & 142 & 30.93 & 9.77 & 21.16 & 3004.72 \\
\hline St. Joseph’s Hospital & 284 & 31.95 & 9.37 & 22.58 & 6412.72 \\
\hline \multicolumn{6}{|l|}{ Health Center } \\
\hline Upstate University Hospital & 412 & 33.21 & 9.38 & 23.83 & 9817.96 \\
\hline \multicolumn{6}{|l|}{ SUNY UMU } \\
\hline \multirow[t]{2}{*}{ Total } & 838 & 32.39 & 9.44 & 22.95 & $19,232.10$ \\
\hline & \multicolumn{5}{|c|}{ Adult Surgery } \\
\hline \multicolumn{6}{|l|}{ January-December 2012} \\
\hline Crouse Hospital & 111 & 35.90 & 17.62 & 18.28 & 2029.08 \\
\hline St. Joseph’s Hospital & 328 & 36.61 & 18.35 & 18.26 & 5989.28 \\
\hline \multicolumn{6}{|l|}{ Health Center } \\
\hline Upstate University Hospital & 504 & 41.54 & 19.07 & 22.47 & $11,324.88$ \\
\hline \multicolumn{6}{|l|}{ SUNY UMU } \\
\hline Total & 943 & 39.16 & 18.65 & 20.51 & $19,340.93$ \\
\hline \multicolumn{6}{|l|}{ January-December 2013} \\
\hline Crouse Hospital & 125 & 33.92 & 17.08 & 16.84 & 2105.00 \\
\hline St. Joseph’s Hospital & 340 & 36.52 & 19.18 & 17.34 & 5895.60 \\
\hline \multicolumn{6}{|l|}{ Health Center } \\
\hline Upstate University Hospital & 456 & 40.23 & 21.06 & 19.17 & 8741.52 \\
\hline \multicolumn{6}{|l|}{ SUNY UMU } \\
\hline Total & 921 & 38.00 & 19.83 & 18.17 & $16,734.57$ \\
\hline
\end{tabular}

Sources: Crouse Hospital, St. Joseph’s Hospital Health Center, and Upstate University Hospital-SUNY UMU; 3M Health Information Systems.

days. This caused the number of excess patient days to decline from 4938 to 2385. Despite this decline, the combined hospitals generated an excess average daily adult medicine census of 6.5 patients during 2013.

At the hospital specific level, adult medicine mean lengths of stay increased by 3.7 percent for Crouse Hospital and by 0.6 percent for St. Joseph's Hospital Health Center and Upstate University Hospital. When combined with severity adjusted national averages, the number of days saved increased for Crouse Hospital while 
the numbers of excess days declined for each of the other hospitals.

The information in Table 1 also demonstrated that, between 2012 and 2013, the mean length of stay for adult surgery in the combined Syracuse hospitals declined from 6.04 to 5.94 days. The 0.10 day decline in the combined hospital stay occurred as the severity of illness of this population rose, as the severity adjusted national average increased from 5.75 to 5.95 days. This caused a change in the hospital utilization for this service from 5927 excess days to 204 days saved. By 2013, the average daily adult surgery stay for the combined hospitals was slightly below the severity adjusted national average.

At the hospital specific level, adult surgery mean lengths of stay remained relatively constant for Crouse Hospital at 4.5 days, increased by 2.3 percent for St. Joseph’s Hospital Health Center, and declined by 5.7 percent for Upstate University Hospital. These changes caused the numbers of days saved to increase at Crouse Hospital and St. Joseph's Hospital Health Center, as well as a substantial decline in the number of excess days at Upstate University Hospital.

The data in Table 2 identify hospital lengths of stay for the Syracuse hospitals for patients with the longest inpatient stays, including 21 or more days, compared with severity adjusted national averages. The data include adult medicine and adult surgery patients in 2012 and 2013.

This information demonstrates that patients with these stays included a small minority of total discharges. For adult medicine, the long stay patients included 2.4 - 2.5 percent of total discharges, 1.6 - 1.7 percent at Crouse Hospital, 2.1 - 2.2 percent at St. Joseph’s Hospital Health Center and 3.1 percent at Upstate University Hospital. For adult surgery, the long stay patients included 4.5 - 4.6 percent of total discharges, 2.3 - 2.7 percent at Crouse Hospital, 3.6 percent at St. Joseph's Hospital Health Center and 7.3 - 7.8 percent at Upstate University Hospital.

At the same time, the long stay patients accounted for large numbers of excess patient days, compared with severity adjusted national averages. For adult medicine, these days amounted to excess days of approximately three weeks per patient. This service produced more than 19,000 excess inpatient days in each of the two years. This amounted to an average daily census of 52 - 53 patients in excess days alone. For adult surgery, the excess stays were lower in each of the two years. The excess average daily census ranged from 45 to 53 patients.

\subsection{Hospital Outcomes}

Data related to the second component of the analysis, which focused on hospital inpatient readmissions, are summarized in Table 3. These data include Potentially Preventable Readmissions for the individual and combined Syracuse hospitals in 2012 and 2013.

This information demonstrated that readmissions by service varied considerably among the Syracuse hospitals during the two year period, but proportions by service were relatively consistent. The largest numbers of readmissions were generated by adult medicine. This service accounted for 79.8 percent of the total for the combined services in 2012 and 81.1 percent of the combined total in 2013. At the hospital specific level, adult medicine accounted for 84 - 85 percent of the total for the combined services at Crouse Hospital, 86 - 87 percent of the combined service total at St. Joseph's Hospital Health Center, and 68 - 72 percent of the combined service total at Upstate University Hospital.

The data also demonstrated that readmission rates varied considerably among the hospital services during the two year period. The highest rates were produced by adult medicine and mental health. At the aggregate level, these rates accounted for between one in nine and one in ten patients.

Readmission rates for adult surgery (6 percent of total discharges) and pediatrics (8 - 9 percent of total discharges) were considerably lower. Readmission rates for the individual hospital services were generally consistent between the two time periods. St. Joseph's Hospital Health Center produced the highest rates for adult medicine and Upstate University Hospital produced the highest rates for mental health for both 2012 and 2013.

The large volume of adult medicine readmissions identified in the study resulted from the fact that patients who were initially admitted for this service as well as patients initially admitted for adult surgery were later readmitted for medicine diagnoses. This pattern was consistent over both time periods. Of the 3625 adult medicine readmissions for the combined Syracuse hospitals in 2012, 665, or 18.3 percent, were initially admitted for adult surgery. Of the 3632 adult medicine readmissions for the combined hospitals in 2013, 672, or 18.5 percent, were initially admitted for adult surgery.

This information, as well as a review of the principal and secondary diagnoses for patients in the study, demonstrated that adult, and especially elderly patients, generally experienced a number of secondary medical 
Table 3. Potentially Preventable Readmissions, Syracuse Hospitals, 2012-2013.

\begin{tabular}{ccccccc|}
\hline & \multicolumn{3}{c}{ Adult Medicine } & \multicolumn{3}{c}{ Adult Surgery } \\
\hline & $\begin{array}{c}\text { Number of } \\
\text { Readmissions }\end{array}$ & $\begin{array}{c}\text { Total } \\
\text { Discharges }\end{array}$ & $\begin{array}{c}\text { Readmissions } \\
\text { Rate }\end{array}$ & $\begin{array}{c}\text { Number of } \\
\text { Readmissions }\end{array}$ & $\begin{array}{c}\text { Total } \\
\text { Discharges }\end{array}$ & $\begin{array}{c}\text { Readmissions } \\
\text { Rate }\end{array}$ \\
\hline Crouse Hospital & & & & & & \\
2012 & 779 & 9043 & 8.61 & 66 & 4506 & 1.46 \\
2013 & 895 & 8528 & 10.49 & 72 & 4400 & 1.64
\end{tabular}

St. Joseph’s Hospital Health Center

$\begin{array}{lllllll}2012 & 1766 & 14,584 & 12.11 & 111 & 7453 & 1.49 \\ 2013 & 1616 & 13,844 & 11.67 & 118 & 7920 & 1.49\end{array}$

Upstate University Hospital-Downtown Campus

\begin{tabular}{|c|c|c|c|c|c|c|}
\hline 2012 & 1080 & 11,553 & 9.35 & 109 & 4812 & 2.27 \\
\hline 2013 & 1121 & 10,355 & 10.83 & 92 & 4628 & 1.99 \\
\hline \multicolumn{7}{|l|}{ Total } \\
\hline 2012 & 3625 & 35,180 & 10.30 & 286 & 16,771 & 1.71 \\
\hline \multirow[t]{3}{*}{2013} & 3632 & 32,727 & 11.10 & 282 & 16,948 & 1.66 \\
\hline & \multicolumn{3}{|c|}{ Mental Health } & \multicolumn{3}{|c|}{ Pediatrics } \\
\hline & $\begin{array}{c}\text { Number of } \\
\text { Readmissions }\end{array}$ & $\begin{array}{c}\text { Total } \\
\text { Discharges }\end{array}$ & $\begin{array}{l}\text { Readmissions } \\
\text { Rate }\end{array}$ & $\begin{array}{c}\text { Number of } \\
\text { Readmissions }\end{array}$ & $\begin{array}{c}\text { Total } \\
\text { Discharges }\end{array}$ & $\begin{array}{c}\text { Readmissions } \\
\text { Rate }\end{array}$ \\
\hline \multicolumn{7}{|c|}{ Crouse Hospital } \\
\hline 2012 & 70 & 1616 & 4.33 & - & - & - \\
\hline 2013 & 98 & 1436 & 6.82 & - & - & - \\
\hline \multicolumn{7}{|c|}{ St. Joseph’s Hospital Health Center } \\
\hline 2012 & 162 & 1339 & 12.10 & - & - & - \\
\hline 2013 & 136 & 1146 & 11.87 & - & - & - \\
\hline \multicolumn{7}{|c|}{ Upstate University Hospital-Downtown Campus } \\
\hline 2012 & 211 & 1199 & 17.60 & 189 & 3939 & 4.80 \\
\hline 2013 & 157 & 1169 & 13.43 & 176 & 3797 & 4.64 \\
\hline \multicolumn{7}{|l|}{ Total } \\
\hline 2012 & 443 & 4154 & 10.66 & 189 & 3939 & 4.80 \\
\hline 2013 & 391 & 3751 & 10.42 & 176 & 3797 & 4.64 \\
\hline
\end{tabular}

Sources: Hospital Executive Council; 3 M Health Information Systems.

diagnoses. These secondary diagnoses were often chronic medical conditions such as heart failure and chronic obstructive pulmonary disease. In about half of the population who experienced readmissions, these medical diagnoses that were secondary on the initial admission became principal diagnoses on the readmission.

Data related to the analysis of hospital inpatient complications are summarized in Table 4. This analysis focused on numbers of secondary diagnoses identified as post admission complications for adult medicine and adult surgery in two of the Syracuse hospitals.

This information demonstrated that, for both time periods, the numbers of inpatient complications for adult medicine patients were higher than for adult surgery patients in each of the two hospitals. Numbers of adult medicine complications were 57 - 58 percent of the total at Crouse Hospital and 60 - 64 percent of the total at St. 
Table 4. Potentially Preventable Complications, Syracuse Hospitals, 2012-2013.

\begin{tabular}{ccccc}
\hline & \multicolumn{2}{c}{ Adult Medicine } & \multicolumn{2}{c}{ Adult Surgery } \\
\hline & $\begin{array}{c}\text { Number of Patients } \\
\text { with Complication }\end{array}$ & $\begin{array}{c}\text { Rate per } 1000 \\
\text { Discharges }\end{array}$ & $\begin{array}{c}\text { Number of Patients } \\
\text { with Complication }\end{array}$ & $\begin{array}{c}\text { Rate per } 1000 \\
\text { Discharges }\end{array}$ \\
\hline $\begin{array}{c}\text { St. Joseph's Hospital } \\
\text { Health Center }\end{array}$ & & & & 39.67 \\
2012 & 547 & 36.74 & 329 & 40.76 \\
2013 & 505 & 35.62 & & 230 \\
Crouse Hospital & & & 103 & 51.04 \\
2012 & 309 & 34.17 & 34.23 & 45.94 \\
\hline
\end{tabular}

Source: Hospital Executive Council.

Joseph's Hospital Health Center. Although the complication rates were higher for adult surgery, the numbers of patients were higher for adult medicine.

\section{Discussion}

As interest in improving the efficiency and outcomes of health care has increased, considerable attention has focused on the fact that relatively small populations of health care patients generate large amounts of utilization and related expenses. Much of this research involves national or regional populations. This study focused on hospital populations which account for large amounts of health care utilization at the community level in the metropolitan area of Syracuse, New York. This perspective is important because local communities are settings for delivery of health care services.

The study data demonstrated that, between the two largest hospital inpatient services, adult medicine patients accounted for a larger number of excess hospital patient days than adult surgery over a two year period. During this period, adult medicine stays increased while adult surgery stays declined. When long stay outlier patients were evaluated, adult medicine also accounted for a larger number of excess inpatient days, an average daily census of 52.7 patients in 2013, although adult medicine outliers comprised only 2.4 - 2.5 percent of discharges while adult surgery patients comprised 4.4 - 4.5 percent of discharges for these services.

For the outcomes indicators, the study data identified a larger preponderance for adult medicine compared with other services. Adult medicine readmissions accounted for 79 - 81 percent of these adverse events for the combined hospital during the two year period. Adult medicine complications accounted for 60 - 62 percent of complications in the two hospitals for which data were available.

A brief consideration of hospital populations suggests a number of reasons for these differences. Adult medicine patients typically experience larger numbers of secondary diagnoses than those in other services. As a result, their severity of illness tends to be higher. Adult medicine admissions are also usually not planned, in contrast to adult surgery and mental health admissions which are frequently scheduled. They also tend to arrive at hospitals through emergency departments. These data clearly demonstrate the challenges that adult medicine patients carry for providers as they attempt to improve the efficiency and outcomes of care in local communities. In the United States, payor reimbursement for the care of these patients frequently does not match the resources required as funding emphasizes surgical specialties and healthier patients. In metropolitan areas such as Syracuse, where local populations are aging or declining, the expenses of caring for these patients can become a major challenge for community providers.

\section{Conclusions}

As efforts to improve the efficiency of health care continue, the care of adult medicine patients within the limits of available resources may become a greater challenge. In the United States, long-stay outlier patients have already proven to be an obstacle to the financial viability of Accountable Care Organizations. 
The data in this study suggest that this population may also challenge the transition from volume to outcomes in the reimbursement of health care. The higher incidence of hospital readmissions and inpatient complications associated with adult medicine in this study suggest that the transition to value-based reimbursement may not be a smooth one.

This information suggests the need for increased attention to identification of populations with increased health care requirements at the community level, where care is delivered. Such an approach can serve the interests of improving health care efficiency and outcomes by providing these patients with the kind of care that they deserve.

\section{References}

[1] Dentzler, S. (2011) Urgent Measures for an Old Problem. Health Affairs, 30, 1626. http://dx.doi.org/10.1377/hlthaff.2011.0961

[2] Auerbach, D.L. and Kellerman, A.L. (2011) A Decade of Health Care Cost Growth Has Wiped out Real Income Gains for an Average U.S. Family. Health Affairs, 30, 1630-1636. http://dx.doi.org/10.1377/hlthaff.2011.0585

[3] Fisher, E.S., Shortell, S.M., Kriendler, S.A., Van Citters, A.D. and Larson, B.K. (2012) A Framework for Evaluating the Formation, Implementation, and Performance of Accountable Care Organizations. Health Affairs, 31, $2368-2378$. http://dx.doi.org/10.1377/hlthaff.2012.0544

[4] Hartman, M., Martin, A.B., Benson, J. and Catlin, A. (2013) National Health Expenditure Accounts Team. National Health Spending in 2011: Overall Growth Remains Low, but Some Payers and Services Show Signs of Acceleration. Health Affairs, 32, 87-98. http://dx.doi.org/10.1377/hlthaff.2012.1206

[5] Martin, A.B., Hartman, M., Whittle, L. and Catlin, A. (2014) National Health Expenditure Accounts Team. National Health Spending in 2012: Rate of Health Spending Growth Remained Low for the Fourth Consecutive Year. Health Affairs, 33, 67-77. http://dx.doi.org/10.1377/hlthaff.2013.1254

[6] Hoonhout, L.H., de Bruijne, M.C., Wagner, C., Zegers, M., Waaijman, R., Spreeuwenberg, P., Asscherman, H., van der Wal, G. and van Tulder, M.W. (2009) Direct Medical Costs of Adverse Events in Dutch Hospitals. BMC Health Services Research, 9, 27. http://dx.doi.org/10.1186/1472-6963-9-27

[7] 3M Health Information Systems (2009) Potentially Preventable Events. 3M Health Information Systems, Wallingford, Conn.

[8] Fuller, R.L., McCullough, E.C., Bao, M.Z. and Averill, R.F. (2009) Estimating the Costs of Potentially Preventable Hospital Acquired Complications. Health Care Financing Review, 30, 17-32.

[9] Hoffman, E.D., Klees, B.S. and Curtis, C.A. (2001) Overview of the Medicare and Medicaid Programs. Health Care Financing Review, Statistical Supplement, 1-102.

[10] Jencks, S.F., Williams, M.V. and Coleman, E.A. (2011) Rehospitalizations among Patients in the Medicare Fee for Service Program. New England Journal of Medicine, 364, 1582. http://dx.doi.org/10.1056/NEJMx110014

[11] Dyer, T., Zhang, J. and Udow-Phillips, M. (2014) The Cost Burden of Disease: United States and Michigan. Center for Healthcare Research \& Transformation, June 2014, Ann Arbor, MI.

[12] Rais, S., Nazerian, A., Ardal, S., Chechulin, Y., Bains, N. and Malikov, K. (2013) High Cost Users of Ontario’s Healthcare Services. Healthcare Policy, 9, 44-51.

[13] Reid, R., Evans, R., Barer, M., Sheps, S., Kerluke, K., McGrail, K., Hertzman, C. and Pagliccia, N. (2003) Conspicuous Consumption: Characterizing High Users of Healthcare Services in one Canadian Province. Journal of Health Services Research and Policy, 8, 215-224. http://dx.doi.org/10.1258/135581903322403281

[14] Lagoe, R., Pasinski, T., Kronenberg, P. and Schaengold, P. (2006) Linking Health Services at the Community Level. Canada Healthcare Quarterly, 9, 60-65. http://dx.doi.org/10.12927/hcq..18229

[15] Lagoe, R.J., Westert, G.P., Kendrick, K., Morreale, G. and Mnich, S. (2005) Managing Hospital Length of Stay Reduction: A Multihospital Approach. Health Care Management Review, 30, 82-92. http://dx.doi.org/10.1097/00004010-200504000-00002

[16] Lagoe, R.J. and Westert, G.P. (2010) Evaluation of Hospital Inpatient Complications: A Planning Approach. BMC Health Services Research, 10, 200. http://dx.doi.org/10.1186/1472-6963-10-200

[17] Lagoe, R.J., Nanno, D.S. and Luziani, M.E. (2013) Clinical Identification of Patients Readmitted to Hospitals: Why Patients Return. BMC Research Notes, 6, 419. http://dx.doi.org/10.1186/1756-0500-6-419 
Scientific Research Publishing (SCIRP) is one of the largest Open Access journal publishers. It is currently publishing more than 200 open access, online, peer-reviewed journals covering a wide range of academic disciplines. SCIRP serves the worldwide academic communities and contributes to the progress and application of science with its publication.

Other selected journals from SCIRP are listed as below. Submit your manuscript to us via either submit@scirp.org or Online Submission Portal.
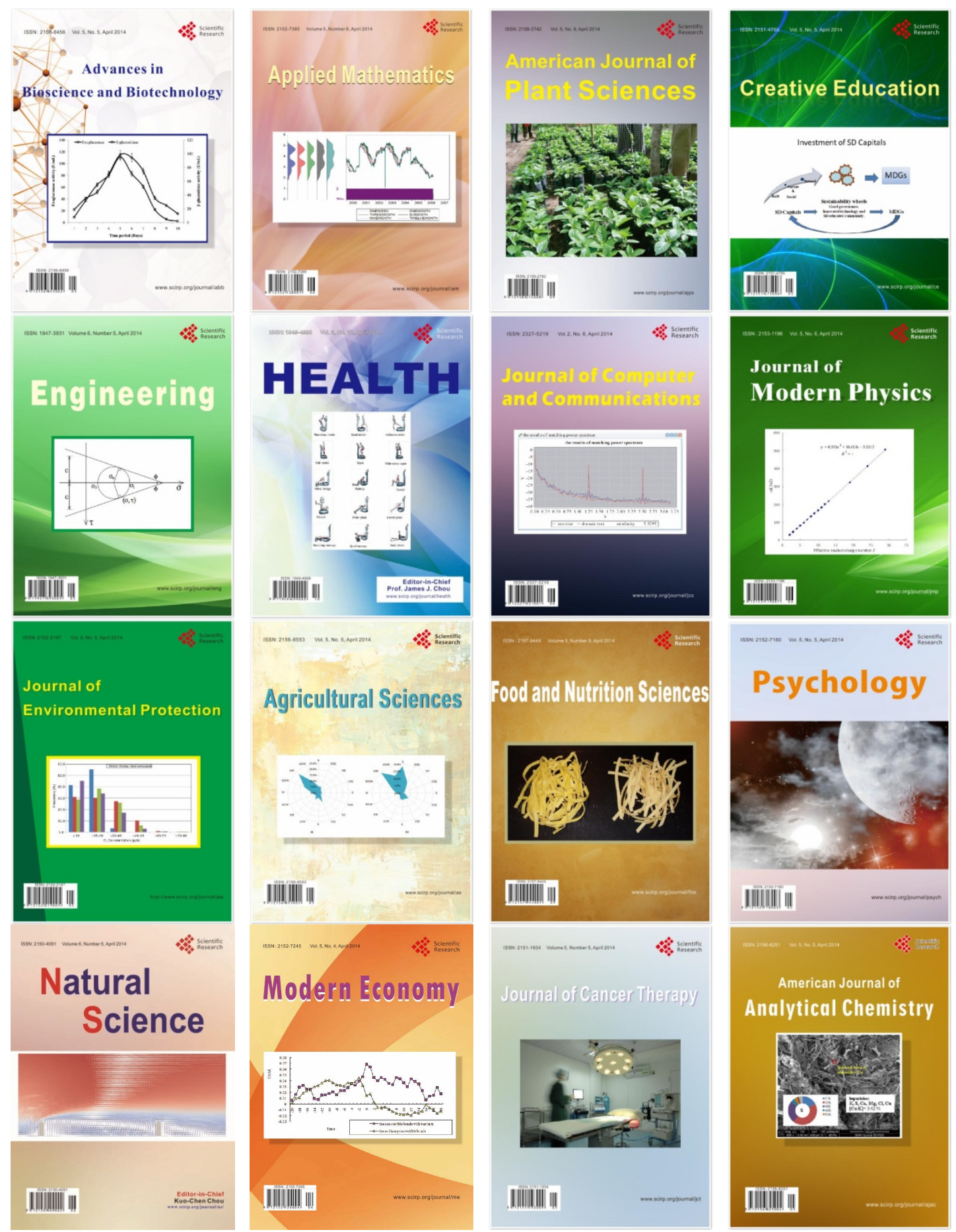